\title{
A Plasmid Isolated from Phytopathogenic Onion Yellows Phytoplasma and Its Heterogeneity in the Pathogenic Phytoplasma Mutant
}

\author{
Tsutomu Kuboyama, ${ }^{1}$ Chieh-Chen Huang, ${ }^{1}$ Xiaoyun Lu, ${ }^{1}$ Toshimi Sawayanagi, ${ }^{1}$ Tokiko Kanazawa, ${ }^{1}$ \\ Takashi Kagami, ${ }^{1}$ Izumi Matsuda, ${ }^{2}$ Tsuneo Tsuchizaki, ${ }^{3}$ and Shigetou Namba ${ }^{1}$ \\ ${ }^{1}$ Laboratory of Bioresource Technology, Graduate School of Agricultural and Life Sciences, The University \\ of Tokyo, Bunkyo-ku, Tokyo 113-8657, Japan; ${ }^{2}$ National Agricultural Research Center, Tsukuba, Ibaraki \\ 305-0856, Japan; ${ }^{3}$ Koibuchi College of Agriculture, Uchihara-machi, Ibaraki 319-0323, Japan \\ Accepted 3 August 1998.
}

\begin{abstract}
A 3.6-kbp DNA fragment was cloned from the extrachromosomal DNA of a pathogenic plant mollicute, onion yellows phytoplasma (OY-W). Sequence analysis of the fragment revealed an open reading frame (ORF) encoding the replication (Rep) protein of rolling-circle replication (RCR)-type plasmids. This result suggests the existence of a plasmid (pOYW1) in OY-W that uses the RCR mechanism. This assumption was confirmed by detecting the single-stranded DNA (ssDNA) of a replication intermediate that is specifically produced by the RCR mechanism. This is the first report on the identification of the replication system of this plasmid and the genes encoded in it. With a DNA fragment including the Rep gene region of pOYW1 used as a probe, Southern and Northern (RNA) blot hybridizations were employed to examine the heterogeneity between the plasmids found in OY-W and a pathogenic mutant (OY-M) isolated from OY-W. Multiple bands were detected in the DNA and RNA extracted from both $O Y-W$ and OY-M infected plants, although the banding patterns were different. Moreover, the copy number of plasmids from OY-W was about 4.2 times greater than that from OY-M. These results indicate constructive heterogeneity between OY-W and OY-M plasmids, and the possibility of a relationship between the plasmid-encoded genes and the pathogenicity of the phytoplasma was suggested.
\end{abstract}

Phytoplasmas (formerly called mycoplasmalike organisms) are prokaryotes that lack a cell wall and are thought to be the causal agents of numerous plant diseases (McCoy et al. 1989; Kirkpatrick 1992). Phytoplasmas inhabit the phloem sieve elements of plants and are transmitted between plants by phloem-feeding insects (Hemmati 1977; Jensen 1959; Tsai 1979). Phytoplasmas are small enough to be able to pass

Corresponding author. Shigetou Namba; Mailing address: Laboratory of Bioresource Technology, Division of Agricultural and Life Sciences, The University of Tokyo, 1-1-1 Midori-cho, Tanashi, Tokyo 188-0002, Japan; Telephone: 81-424-69-3125; Fax: 81-424-69-8786; E-mail: snamba@ims.u-tokyo.ac.jp

Nucleotide and/or amino acid sequence data of Rep and SSB genes are to be found at the GenBank data base as accession numbers AB010421 and AB010422, respectively. through bacteriological filters, and, like mycoplasmas, are resistant to antibiotics that interfere with cell wall formation. Due to the inability to culture phytoplasmas in vitro and isolate phytoplasmas from the relatively small amount of phloem tissue present in plants, phytoplasmas are among the most poorly characterized groups of plant pathogens.

Onion yellows phytoplasma (OY-W), which was isolated in Saga Prefecture, Japan, in May 1982, is the causal agent of onion yellows disease and is transmitted by Macrosteles striifrons Anufriew. OY-W induces a wide variety of symptoms in its plant host including virescence (greening of the floral tissue), yellowing, phyllody (leaflike petals and sepals), stunting (shortened internodes and dwarfed leaves and flowers), and proliferation (witches'-broom) (Shiomi et al. 1996).

In our previous work, a pathogenic mutant (OY-M) was isolated from OY-W when it was transferred by the leafhopper vector, $M$. striifrons, on the host plant garland chrysanthemum, Chrysanthemum coronarium (T. Sawayanagi, T. Shiomi, X. Lu, T. Kanazawa, S. Arai, K. Oshima, C.-C. Huang, T. Kuboyama, I. Matsuda, T. Tsuchizaki, and S. Namba, unpublished). The plants infected by OY-M had only slightly shortened internodes and the other symptoms of infection did not appear. The reproducibility of symptoms and the stability of the mildly pathogenic characteristics of the "mutant type" phytoplasma in infected plants were confirmed by using the insect vector to transmit the pathogen to healthy plants more than 60 times over 4 years. The successful finding of the pathogenic mutant prompted us to characterize the genetic background responsible for the differences in pathogenicity between OY-W and OY-M. Since there have been no reports on genes responsible for the pathogenicity of phytoplasmas, this work was carried out in hopes of finding some such genes.

Extrachromosomal DNA, including single-stranded (ss) and double-stranded (ds) DNA, associated with spiroplasma, mycoplasma, and Acholeplasma viruses has been described (Maniloff 1988; Razin 1985). The mollicute plasmids characterized to date are cryptic, and transfer of plasmid DNA between mollicutes has not yet been demonstrated (Kuske and Kirkpatrick 1990). Although the existence of extrachromosomal DNA has been reported in some phytoplasmas (Kuske and Kirkpatrick 1990; Nakashima and Hayashi 1997), there is extremely little information on the encoded protein. However, plasmid DNA from 
bacteria has been shown to encode some biologically important genes, which affect chemical tolerance, pathogenicity, virulence, and gene transfer (Davies and Rownd 1972; Panopoulos and Peet 1985). Plant-pathogenic bacterial plasmids, like those in Agrobacterium spp., are essential for host-parasite interaction (Winans 1992). In phytoplasmas, the biological functions of the plasmids and extrachromosomal DNAs have not yet been reported. The possibility that phytoplasmas may encode genes in the extrachromosomal DNA that are related to pathogenicity encouraged us to focus on this subject.

In this paper, a 3.6-kbp fragment of extrachromosomal DNA was cloned from OY-W and sequenced. With a part of the fragment used as a probe, the heterogeneity between the wild-type onion yellows phytoplasma and its pathogenic mutant was examined.

\section{RESULTS}

\section{Cloning and sequence analysis.}

Since the copy number of plasmids is considered to be higher than that of the genome, shotgun cloning of total DNA from the phytoplasma-enriched plant extract is expected to clone the plasmid DNA predominantly. From the preliminary experiments, almost no DNA components were detected from plant nuclei, mitochondrium, or chloroplast in the total phytoplasma-enriched plant extract. As we expected, one clone (WH-9), appeared to be a plasmid fragment after sizing by Southern hybridization with electrophoresis of undigested DNA extracted from healthy plants and plants infected with OY-W. Further sequence analysis revealed that the insert of W-H-9 was 3,564 nucleotides in length and appeared to contain five open reading frames (ORFs) (Fig. 1). ORF5 (225 amino acids [aa]) was similar ( $22.8 \%$ identity) to the putative replication (Rep) protein of the plasmid pKMK1 from Mycoplasma mycoides subsp. mycoides (Fig. 2) (King and Dybvig 1992). ORF5 was also similar to the Rep proteins of Leuconostoc lactis 533 plasmid pCI411 (23.8\% identity) (Coffey et al. 1994), Streptococcus pneumoniae plasmid pE194 (22.4\% identity), and pLS1 (18.6\% identity) (Lacks et al. 1986; Horinouchi and Weisblum 1982; Villafane et al. 1987) (Fig. 2). These Rep proteins are encoded in plasmids belonging to the pLS1 family of rolling-circle replication (RCR)-type plasmids (del Solar et al. 1993). Five conserved motifs, called $\mathrm{R}-\mathrm{I}$ to $\mathrm{R}-\mathrm{V}$, have been described previously in the Rep proteins of the pLS1 family (Fig. 2) (del Solar et al. 1993). ORF5 of $\mathrm{W}-\mathrm{H}-9$ has four of these five motifs, but lacks the first. ORF5 has two conserved tyrosine (Y) residues found in all Rep proteins of the pLS1 family. One is the $\mathrm{Y}$ residue, located at position 104 in region R-IV, that is known to be involved in the nucleophilic attack of Rep protein on its cognate DNA, and the other is located at position 116 in region R-V (Moscoso et al. 1997; del Solar et al. 1993). ORF5 also has two conserved histidine $(\mathrm{H})$ residues in region $\mathrm{R}$-III. Both $\mathrm{H}$ residues have been proposed to act as metal ligands (Ilyina and Koonin 1992). The size of ORF5 protein ( 225 aa residues) is close to that of other Rep proteins of the pLS1 family plasmids. This suggests that ORF5 seems to encode almost the entire gene. However, the cloning site interrupted the $3^{\prime}$ end of ORF1 and the stop codon of ORF1 was not found in the W-H-9 insert.

ORF4 (103 aa) showed similarity (36\% identity) to the $\mathrm{N}$ terminal two-thirds of an ssDNA binding (SSB) protein of $\mathrm{Ba}$ - cillus subtilis (Ogasawara et al. 1994) (Fig. 3). The ORF4 from $\mathrm{W}-\mathrm{H}-9$ lacked the $\mathrm{C}$-terminal glycine-rich region that is present in SSB proteins encoded in the chromosomes of $B$. subtilis and Serratia marcescens (de Vries and Wackernagel 1993). SSBs lacking the C-terminal acidic region were previously reported in the chromosome of $B$. subtilis (26.1\% identity with ORF4) (Presecan et al. 1997) and some conjugative plasmids, such as pGO1 (26.8\% identity with ORF4) (Morton et al. 1993) and RK2 (30\% identity with ORF4) (Smith and

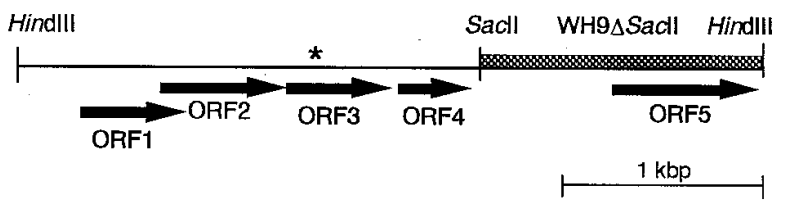

Fig. 1. Open readings frames (ORFs) of pOYW1 and the probe, WH9 $\Delta$ SacII. ORFs are identified by arrows. Shadowed region was used as the probe. A sequence similar to the double-stranded origin of replication of the pC194 family of rolling-circle replication (RCR) plasmids is marked by an asterisk.

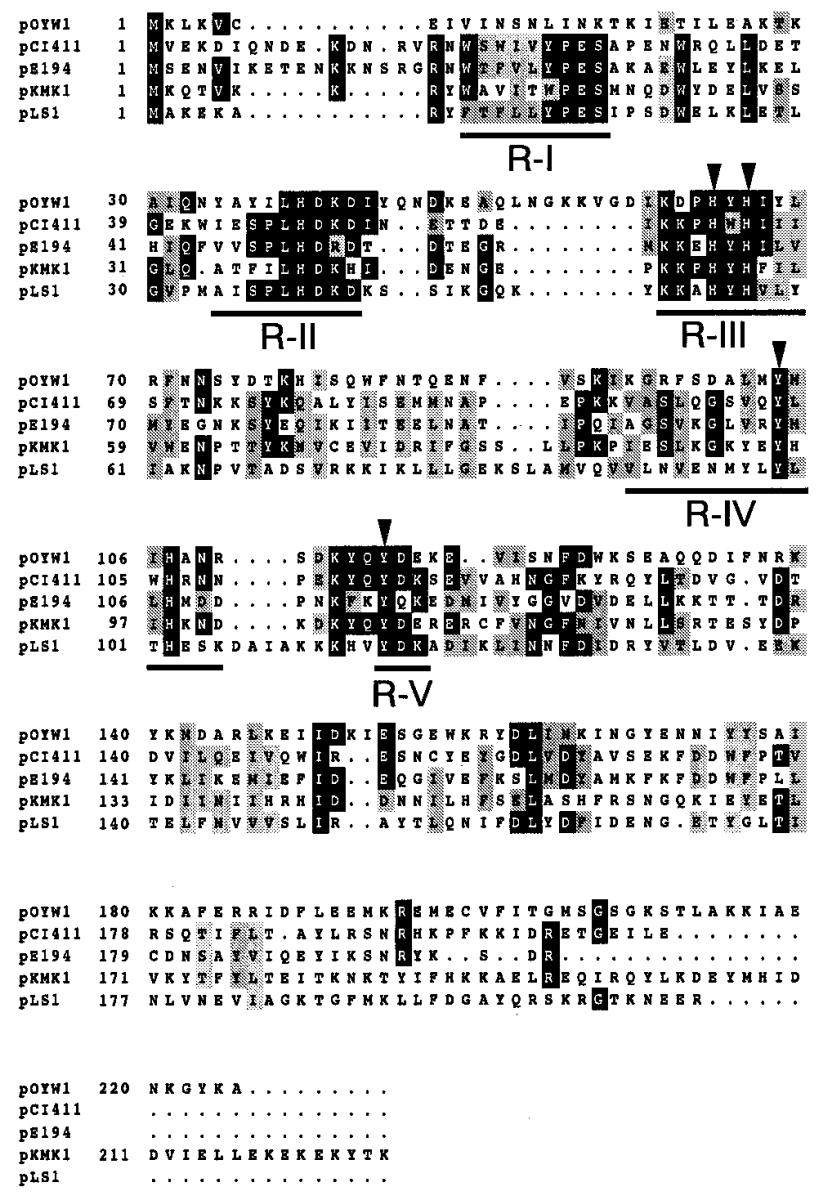

Fig. 2. Comparison of the deduced amino acid sequence of open reading frame (ORF) 5 with other replication (Rep) genes from rolling-circle replication (RCR) plasmids. Putative common domains of pLS1 family plasmids (R-I, R-II, R-III, R-IV, and R-V), as described in the text, are marked. Arrows point out the conserved histadine (H; R-III domain) and tyrosine (Y; domains R-IV and $-\mathrm{V})$ residues. Dark boxed residues = identical residues; shaded regions = homologous residues; dashes = gaps. Nucleotide sequence of ORF5 was submitted to the GenBank nucleotide sequence data base and assigned accession number AB010421. 
Thomas 1984). The rest of the deduced amino acid sequences in the putative ORFs contained in W-H-9 did not show significant homology with previously reported proteins.

Although ORF5 was homologous to the Rep protein of pLS1 family, the sequence TACTACGA, the nick site for double-strand origin (DSO) conserved in the pLS1 family, was not found. However, a sequence similar to the nick site conserved in the pC194 family of RCR plasmids was found downstream from ORF5 (Figs. 1 and 4).

\section{W-H-9 is a fragment derived from an RCR plasmid of OY-W.}

The sequence analyses indicated that the insert of W-H-9 is a fragment derived from plasmid DNA. This plasmid was designated as pOYW1. To confirm that $\mathrm{W}-\mathrm{H}-9$ was derived from RCR plasmid DNA of OY-W, the presence of ssDNA was tested by the methods of te Riele et. al. (1986). DNA extracted from healthy plants and plants infected with OY-W
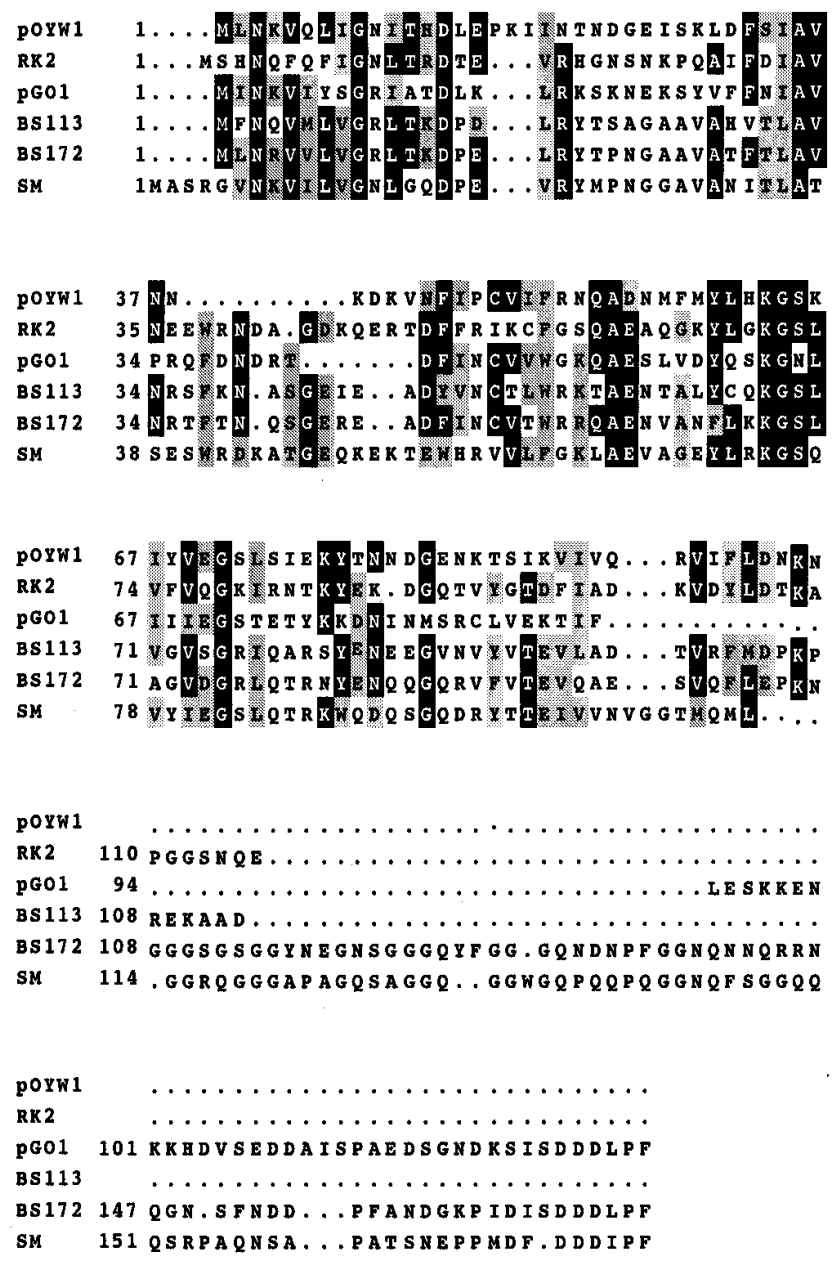

Fig. 3. An alignment of protein sequences from the open reading frame (ORF) 4 amino acid sequence and other single-stranded DNA binding (SSB) proteins. pGO1: SSB of pGO1 plasmid from Staphylococcus aureus. RK2: SSB of RK2 plasmid from Escherichia coli. BS113: SSB encoded in chromosome from Bacillus subtilis (Presecan et al. 1997). BS172: SSB encoded in chromosome from Bacillus subtilis (Ogasawara et al. 1994). SM: SSB from Serratia marcescens. Dark boxed residues = identical residues; shaded regions $=$ homologous residues; dashes $=$ gaps. Nucleotide sequence of ORF4 was submitted to the GenBank nucleotide sequence database and assigned accession number AB010422. was electrophoresed in the gel and then transferred to a nylon membrane and probed with WH9 $\Delta$ SacII, which contains the putative Rep gene region of W-H-9 (Fig. 1). Since plasmids using the RCR type mechanism will produce a specific ssDNA replication intermediate, DNA extracts used for hybridization were not denatured.

The probe WH9 4 SacII hybridized only with the ssDNA from OY-W infected plants while no hybridization signals were detected in either healthy plant extract (Fig. 5) or DNA treated with $\mathrm{S} 1$ nuclease prior to electrophoresis. This result confirms that W-H-9 originated from the OY-W plasmid and that pOYW1 replicates by the RCR mechanism.

\section{Band patterns of OY-W and OY-M.}

DNA extracted from plants infected with either OY-W or OY-M was denatured in the gel and probed with WH9 $\Delta$ SacII. Multiple bands were detected in DNA extracted from both OY-W and OY-M infected plants. However, the pattern of bands differed (Fig. 6A).

To avoid the varying physical forms of plasmid (supercoiled, open circle, linear, or ssDNA replicating intermediates) in the background, DNA extracts digested with endonuclease were

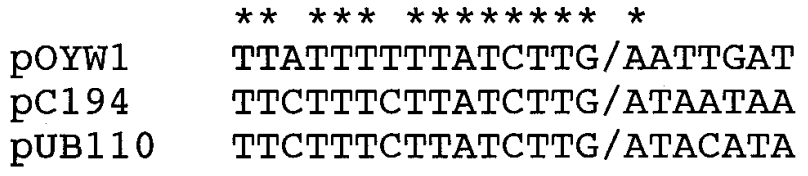

Fig. 4. Alignment of the double-stranded origin nick site of the pC194 group with a homologous sequence from pOYW1. Conserved residues indicated by asterisk. Nick site of pC194 and a putative nick site indicated by slash.

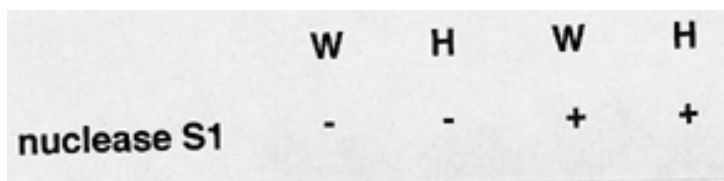

Fig. 5. Southern blot hybridization analysis for detecting single-stranded DNA. DNA from healthy and OY-W diseased garland chrysanthemums, treated $(+)$ or untreated $(-)$ with nuclease S1 and not denatured were transferred to nylon membrane. Digoxygenin-labeled WH9LSacII was used as a probe. H: DNA from a healthy plant; W: DNA from an OY-W diseased plant. 
also prepared for further examinations. Four bands (7.8, 5.4, 3.8 , and $2.6 \mathrm{kbp}$ ) were detected in the lanes from OY-W and only two bands (4.9 and $3.8 \mathrm{kbp}$ ) were detected in the lanes from OY-M (Fig. 6). These results strongly suggest constructive heterogeneity between OY-W and OY-M plasmids.

\section{Comparisons of copy number of plasmids between OY-W and OY-M.}

An ability to multiply and spread within both the insect vector and plant host was shown to be the same for the OY-W and OY$\mathrm{M}$ by molecular biological and electron microscopic studies ( $\mathrm{T}$. Sawayanagi, T. Shiomi, X. Lu, T. Kanazawa, S. Arai, K. Oshima, C.-C. Huang, T. Kuboyama, I. Matsuda, T. Tsuchizaki, and S. Namba, unpublished). The data indicated that there is no difference in the amount of the phytoplasmal bodies between the OY-W and OY-M. To compare the copy number of plasmids in OY-W and OY-M, the ratio of plasmids to genome was calculated from the signal strength of the Southern blot hybridization (Fig. 7) (Asaka et al. 1994). A clone, I-H-5, which has just a single copy in the OY-W and OY-M genomes (data not shown), was selected to use as a control DNA probe. After the amount of phytoplasma genomic DNA on the membrane with the probe I-H-5 was measured, the same membrane was dehybridized and reprobed with WH9 4 SacII (Fig. 7) (Krueger and Williams 1995). After the second genomic Southern hybridization, the signals from both strains were calibrated with the signals from the control DNA probe (I-H-5). The

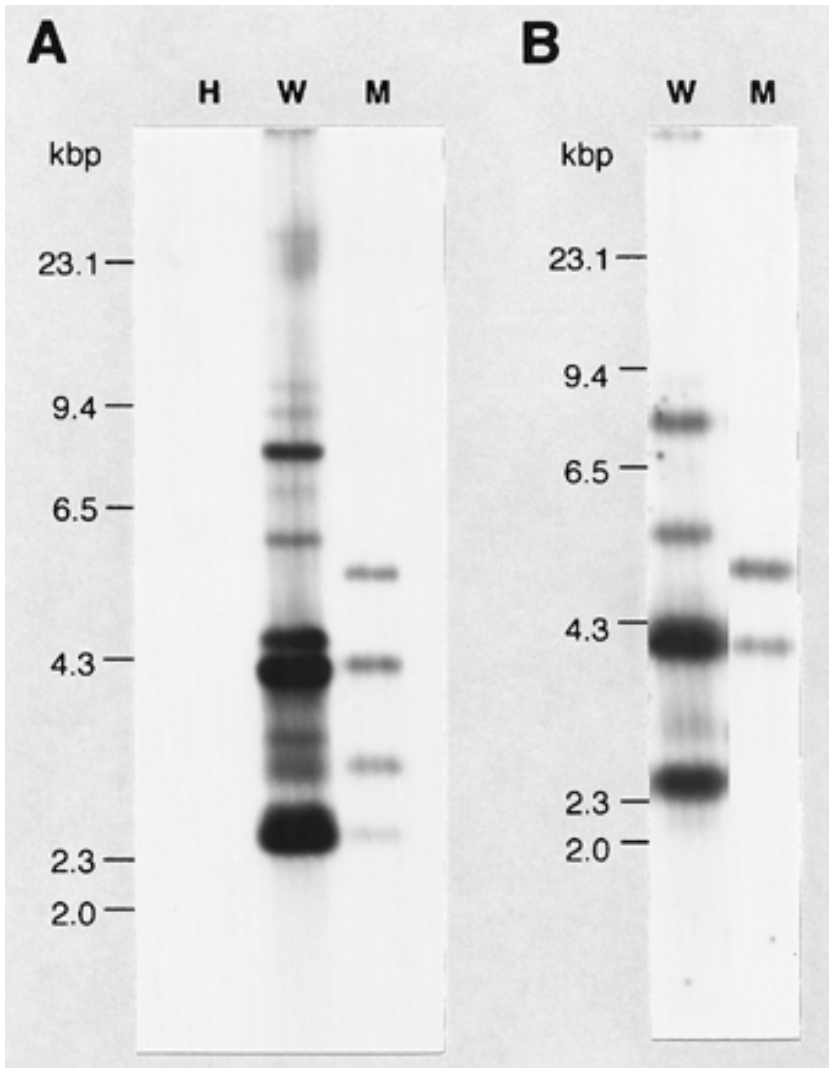

Fig. 6. Southern blot hybridization analysis for comparison between OY$\mathrm{W}$ and OY-M diseased garland chrysanthemums. Undigested DNA (A) and DNA digested with EcoRI (B) were hybridized with WH9 $\Delta$ SacII probe. H: DNA from a healthy plant; W: DNA from an OY-W diseased plant; M: DNA from an OY-M diseased plant. signal ratio of WH9 4 SacII to I-H-5 was approximately 9.75 in OY-W and approximately 2.33 in OY-M. These results suggest that the plasmid copy number in OY-W is 4.2 times greater than in OY-M. The same experiments were performed two more times, and almost the same results were reproduced.

\section{Transcripts detected in OY-W and OY-M.}

RNA extracted from the phytoplasma-enriched fraction of OY-W or OY-M infected plants was analyzed by Northern hybridization with W-H-9 as a probe (Fig. 8). Transcripts 0.86 , $1.2,1.5,1.9,2.8$, and $4.5 \mathrm{~kb}$ in length were detected in the OY-W lane and transcripts $1.4,1.8,2.5$, and $3.5 \mathrm{~kb}$ long were detected in the OY-M lane. The sizes of the transcripts were different in the two strains.

\section{DISCUSSION}

The deduced protein encoded by ORF5 of W-H-9 was identified as a Rep protein of the RCR plasmid and the detection of ssDNA replication intermediates demonstrated that phytoplasmal plasmid pOYW1 uses an RCR type replication mechanism. Although the $3^{\prime}$ end of ORF5 was interrupted by the cloning site and the stop codon of ORF5 was not found, molecular cloning with another endonuclease is now in progress to elucidate the full length of the Rep gene. Homology analysis showed that ORF5 is similar to the Rep genes of pLS1 family plasmids. Among these Rep genes, the Rep gene of Mycoplasma mycoi-

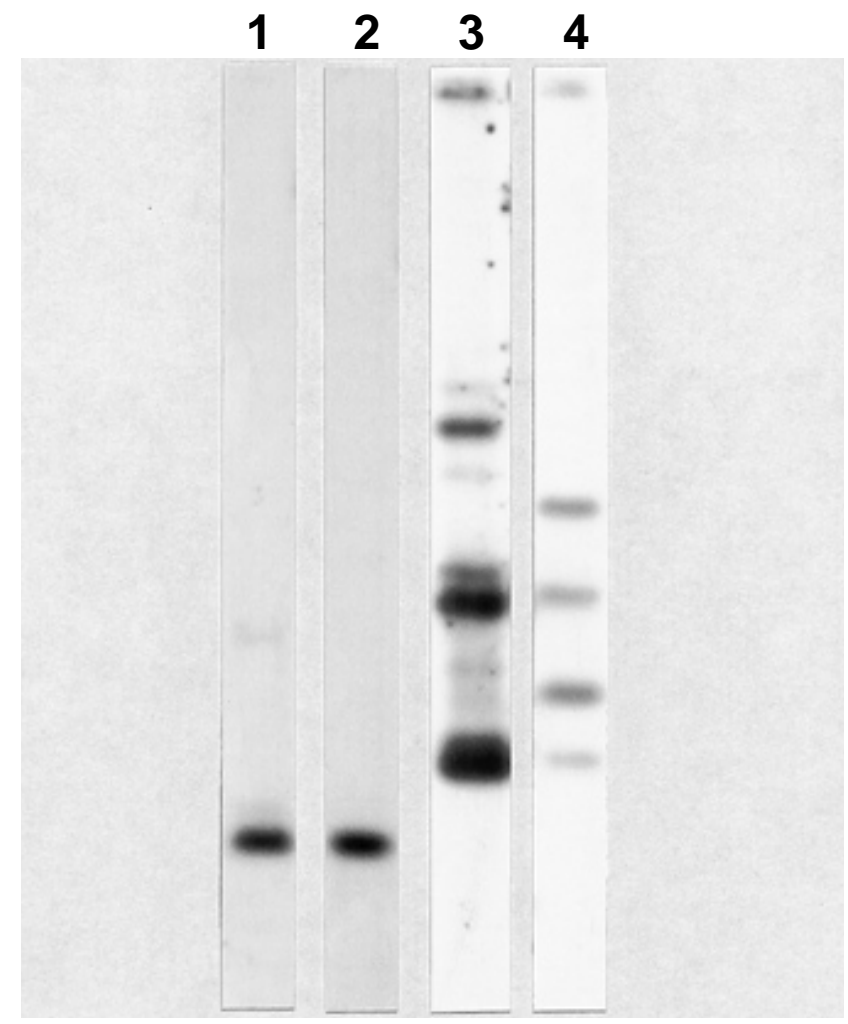

Fig. 7. Southern blot hybridization to compare copy numbers of plasmids from OY-W and OY-M. DNA from OY-W (lanes 1 and 3) or OY-M (lanes 2 and 4) diseased plants, digested with HindIII, was transferred to a nylon membrane after agarose gel electrophoresis. Membrane was hybridized with I-H-5 probe, which is a single-copy gene in the OYchromosome (lanes 1 and 2). Then the same membrane was reprobed with WH9ASacII (lanes 3 and 4). 
des plasmid pKMK1 shows some similarity with the Rep gene of pOYW1. This seems to be very reasonable when considered from a taxonomic point of view. However, pOYW1 differs from the pLS1 family of RCR plasmids in the following ways. First, ORF5 of W-H-9 does not have the region, R-I, that is the first conserved region in the Rep genes of the pLS1 family. It was speculated that the function of motif R-I is to participate in the recognition of sequences surrounding the Rep gene nick site and/or in the recognition of secondary structures in the nick region (del Solar 1993). This might explain why we could not identify the nick site sequence that is conserved in pLS1 family in W-H-9. Second, RCR plasmids that also encode the SSB gene have not been reported previously. Since the host-encoded SSB is believed to be involved in the replication process of RCR plasmids (del Solar 1993), there seems to be no need for RCR plasmids to encode SSB. Aside from DNA replication, SSBs have been shown to be involved in both recombination and repair (Meyer and Laine 1990). In fact, some SSBs have been reported to be encoded by conjugative plasmids and involved in DNA transfer by protecting ssDNA from host nuclease. This indicates the possibility that the SSB of pOYW1 could be involved in plasmid transfer between phytoplasmas. It has been shown that some RCR plasmids are mobilized by the large conjugative plasmid pGO1 that encodes SSB (Archer and Johnston 1983). The real function of SSB of pOYW1 remains a very interesting subject for further elucidation.

In Southern hybridization, multiple bands were detected by WH9 $\Delta$ SacII probe in the DNA extracted from both OY-W and OY-M diseased plants. Multiple bands were also detected in the endonuclease-digested DNA from OY-W and OY-M. In general, RCR increases the chance of replication error at replication and the frequency of recombination of plasmids, both of which may increase diversity (Janniére et al. 1993). So it is

\section{2}

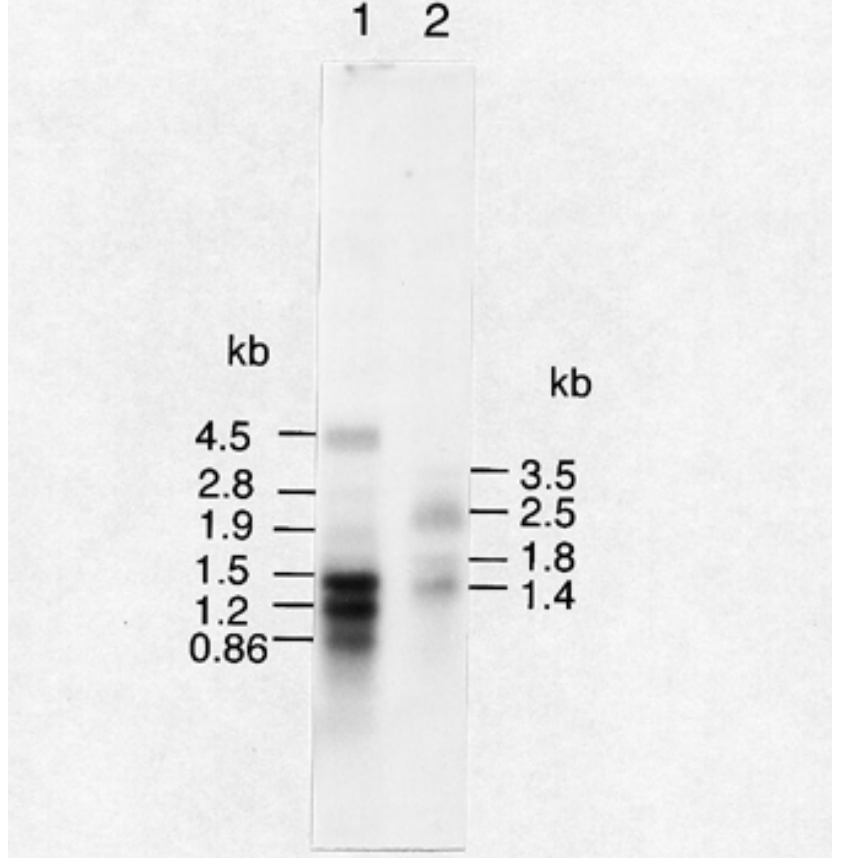

Fig. 8. Comparison of transcript accumulation between RNA extracted from OY-W diseased and OY-M diseased plants. RNA loaded in each lane was extracted from an equal amount of tissue $(0.5 \mathrm{~g}$ of plant tissue per lane). plausible that there might be a variety of RCR plasmids in OY-W and OY-M. However, the fact that the pattern of bands differed in OY-W and OY-M indicates constructive heterogeneity between OY-W and OY-M plasmids. Although the functions of the ORFs encoded in pOYW1 have not been determined yet, it has been shown that plasmid-encoded genes are important in determining pathogenicity and virulence in several pathogenic bacteria (Panopoulos and Peet 1985). The constructive heterogeneity between plasmids from OY-W and OY-M supports the differentiation of genes encoded by plasmids. It also may explain the difference in pathogenicity between OY-W and OY-M. In addition, comparison of the copy number of these plasmids with the WH9 4 SacII probe revealed that the total copy number of plasmids was reduced in OY-M. This indicates the effect of gene dosage may be another factor that affects the pathogenicity of OY-M.

Several sizes of transcripts accumulated in the RNA extracted from both OY-W and OY-M infected plants. These transcripts have different sizes in OY-W and OY-M. It has not yet been determined whether these multiple bands reflect the species of plasmids. The number of transcripts was roughly estimated by calibrating the amount of RNA with DNA dot blot hybridization. It is likely that more transcripts accumulated in OY-W than in OY-M. However, a precise estimation of transcripts is difficult, because there are no available internal controls that are expressed constitutively in phytoplasma and the transcripts are so unique that they do not cross hybridize with the host RNA.

In this paper, we report the differences in both the amount of DNA and transcripts and the structure of plasmids between OY-W and OY-M. However, to clarify whether the plasmids are involved in the pathogenicity of phytoplasma, it is still necessary to determine the whole primary structure of pOYW1 and the differences in the gene organization between plasmids from both isolates. Further investigations will provide some new insights about how these nonculturable, pathogenic, wall-less bacteria cause symptoms in their hosts.

\section{MATERIALS AND METHODS}

\section{Phytoplasmas and phytoplasma-infected plants.}

A wild-type line of onion yellows phytoplasma (OY-W), which was isolated in Saga Prefecture, Japan, in May 1982 (Shiomi et al. 1996), and a natural pathogenic mutant (OY-M) of OY-W, which arose during maintenance of OY-W in a greenhouse (T. Sawayanagi, T. Shiomi, X. Lu, T. Kanazawa, S. Arai, K. Oshima, C.-C. Huang, T. Kuboyama, I. Matsuda, T. Tsuchizaki, and S. Namba, unpublished), were used for these experiments. Adult leafhopper vectors (M. striifrons Anufriew) collected from $C$. japonica fields were confined in a cage with rice plants (Oryza sativa cv. Kinuhikari). Rice is not a host for either OY-W or OY-M. After the first generation nymphs appeared, the adults were removed from the cage. When the first generation matured, the adults, which did not carry any agent that would infect garland chrysanthemum (Chrysanthemum coronarium), were transferred from the rice plants to healthy garland chrysanthemum plants and confirmed to carry no agent by observation of symptoms and detection of phytoplasmas with polymerase chain reaction (PCR) as reported previously (Namba et al. 1993). The plants were sprayed several times with insecticide (DDVP 0.5\% solution; Sankyo, Tokyo) to kill the insects and then transferred to a greenhouse 
(20 to $30^{\circ} \mathrm{C}$ ). About two months later, DNA and/or RNA was extracted from plants with well-developed symptoms.

\section{Preparation of phytoplasma-enriched fraction from infected garland chrysanthemum plants.}

Phytoplasma-enriched fraction from infected garland chrysanthemum plants was prepared as reported previously (Lee and Davis 1988). Twenty grams of young leaves showing early stage symptoms was surface sterilized with $1 \%$ sodium hypochlorite for $5 \mathrm{~min}$ and then rinsed three times in sterile, distilled water. Midribs of leaves cut longitudinally with sharp forceps in such a way that only central portions containing vascular tissues were transferred aseptically into petri plates containing macerating enzymes in solution (Lee and Davis 1983) were incubated overnight in the dark at $4^{\circ} \mathrm{C}$ to digest the vascular tissues. Xylem tissue removed from partially digested phloem tissue with forceps was transferred into a petri plate containing $15 \mathrm{ml}$ of sterile macerating medium (0.5 M mannitol, $30 \mathrm{mM}$ HEPES [ $N$-2-hydroxyethylpiperazine- $N$-2-ethanesulfonic acid] buffer, $0.1 \%$ polyvinylpyrrolidone [PVP] $40, \mathrm{pH} 7.0)$. The sieve elements were gently macerated with glass tissue homogenizers to release phytoplasmas into the macerating medium.

To remove the host organelles and cell wall debris, the suspension was clarified at least once by centrifugation at $(1,000$ $\times g$ for 10 min. The supernatant liquids, which contained onion yellows phytoplasmas. were centrifuged at $18,300 \times g$ for $40 \mathrm{~min}$. The resulting pellets were resuspended in $2 \mathrm{ml}$ of phosphate-buffered saline (PBS)-sucrose solution (0.145 M $\mathrm{NaCl}, 0.008 \mathrm{M} \mathrm{Na}_{2} \mathrm{HPO}_{4}, 0.0014 \mathrm{M} \mathrm{NaH}_{2} \mathrm{PO}_{4}, 0.146 \mathrm{M}$ sucrose, $\mathrm{pH}$ 7.2) and stored at $-80^{\circ} \mathrm{C}$.

\section{Isolation of nucleic acid from onion yellows phytoplasma-enriched preparation.}

DNA was extracted from the phytoplasma-enriched fraction basically following the previously described procedure (Lee and Davis 1988). The onion yellows phytoplasmas in PBSsucrose were concentrated by centrifugation at $24,350 \times g$. The pellet was then resuspended in $2 \mathrm{ml}$ of DNA extraction buffer (0.1 M Tris, 0.05 M EDTA, $0.05 \mathrm{M} \mathrm{NaCl}, \mathrm{pH}$ 8.0). Two hundred microliters of $10 \%$ sodium dodecyl sulfate (SDS) and $2 \mu \mathrm{l}$ of 2 -mercaptoethanol were added. The components were mixed thoroughly by vortexing. The mixture was incubated at $65^{\circ} \mathrm{C}$ in a heat block for $10 \mathrm{~min}$ and then cooled to room temperature. The resulting clear solution was centrifuged at 5,000 $\times g$. The supernatant was treated with proteinase $\mathrm{K}$ (final concentration, $1 \mathrm{mg} / \mathrm{ml}$ ) and incubated at $37^{\circ} \mathrm{C}$ for $1 \mathrm{~h}$. The reactant was extracted twice with $2 \mathrm{ml}$ of Tris-EDTA (TE; $10 \mathrm{mM}$ Tris $\mathrm{HCl}, 1 \mathrm{mM}$ EDTA, $\mathrm{pH}$ 8.0) saturated phenol and twice with $2 \mathrm{ml}$ of chlorofoamyl alcohol (24:1). The aqueous phase was added with the 2 volumes of cold $95 \%$ ethanol. The crude onion yellows phytoplasma nucleic acids were precipitated by centrifugation at $24,350 \times g$ for $20 \mathrm{~min}$. The pellet (nucleic acid) was air dried and resuspended in $100 \mu \mathrm{l}$ of TE buffer, to which was added $0.6 \mathrm{vol}$ of $20 \%$ PEG (polyethylene glycol 6000 ) and $2.5 \mathrm{M} \mathrm{NaCl}$, and incubated on ice for an hour. After centrifugation at $24,350 \times g$ for $30 \mathrm{~min}$, the pellet was washed with $70 \%$ ethanol and dried. The resulting pellet was resuspended in $25 \mu 1$ of TE buffer. This DNA extracted from onion yellows phytoplasma-enriched fraction or healthy garland chrysanthemums was used to construct a DNA library.

For colony hybridization and Southern hybridization, the
DNA from OY-W diseased, OY-M diseased, and healthy plants was isolated from the phytoplasma-enriched fractions of garland chrysanthemum as described previously (Kuske and Kirkpatrick 1990).

To select phytoplasma-DNA clones, total clones were screened by colony hybridization with restriction enzymedigested DNAs extracted from healthy plants or phytoplasmainfected plants. To isolate RNA, the phytoplasma-enriched pellet was lysed in ISOGEN (Nippon Gene, Toyama, Japan) reagent, after high-speed centrifugation $(17,500 \times g, 30 \mathrm{~min})$. Then, the RNA was isolated according to the method of Chomczynski (1993).

\section{Cloning of phytoplasma DNA.}

To clone the OY-W DNA, total DNA isolated from the OYW enriched fraction was completely digested with HindIII restriction endonuclease and ligated into pUC18 cloning vector. Escherichia coli JM109 was transformed as the host for the recombinant DNA. The DNA library obtained was used for differential screening. Probes were prepared from DNA isolated from OY-W infected or healthy plants, digested with HindIII. Clones that preferentially hybridized to the probe prepared from OY-W infected plant were isolated.

\section{DNA sequencing and homology analysis.}

The OY-W-specific DNA insert was sequenced with Taq FS DNA polymerase and fluorescent-dideoxy terminators with a cycle sequencing method following the commercially supplied protocol (Perkin Elmer Applied Biosystems, Foster City, CA). The resultant DNA fragments were separated by electrophoresis and analyzed with an automated 377 DNA Sequencer (Applied Biosystems, Foster City, CA). The similarity of all five ORFs to other known determinants was ascertained by computer-assisted homology analyses with sequence interpretation tools found on-line from the Institute of Medical Science (University of Tokyo, Tokyo) and the BLAST algorithm (Altschul et al. 1990). Amino acid sequences of proteins that showed similarity with each ORF were aligned by Clustal W version 1.6 (Thompson et al. 1994).

\section{Southern blot analysis.}

Southern blot analysis was performed with the digoxigenin (DIG) luminescent detection kit (Boehringer Mannheim Biochemicals, Mannheim, Germany), following the manufacturer's instructions. DNA from the phytoplasma-enriched fraction was digested with the restriction enzymes HindIII, SpeI, EcoRI, and $X b a I$. A 1,358-bp DNA fragment that contained ORF5 was subcloned into the plasmid vector pUC18 and used for probe labeling with PCR DIG labeling mix (Boehringer Mannheim Biochemicals). PCR was performed with the universal primers M13-20 and M13-Reverse, to incorporate DIG-labeled dUTPs into the probes. The membrane was prehybridized in hybridization buffer $(5 \times \mathrm{SSC}$, $[1 \times \mathrm{SSC}$ is $0.15 \mathrm{M} \mathrm{NaCl}$ plus $0.015 \mathrm{M}$ sodium citrate] $2 \%$ blocking reagent supplied by the DIG luminescent detection kit [Boehringer Mannheim Biochemicals], $0.1 \% \mathrm{~N}$-lauroylsarcosine, $7 \% \mathrm{SDS}, 50 \mathrm{mM}$ sodium phosphate buffer [pH 7.0], $50 \%$ formamide) at $42^{\circ} \mathrm{C}$ for $1 \mathrm{~h}$ (Sambrook et al., 1989). Hybridization was carried out at $42^{\circ} \mathrm{C}$ overnight in hybridization buffer that contained the denatured probe. After hybridization, the membrane was washed twice in $2 \times$ SSC and $0.1 \%$ SDS for $5 \mathrm{~min}$ each, and then washed twice in $0.1 \times \mathrm{SSC}$ 
and $0.1 \%$ SDS at $68^{\circ} \mathrm{C}$ for 15 min each. Hybridized probes were detected by following the manufacturer's guidelines (Boehringer Mannheim Biochemicals). The strength of the signals was analyzed with a densitometer PDI (Quantity One System, Toyobo, Tokyo). The presence of plasmid ssDNA was determined by the methods of te Riele et al. (1986).

\section{Northern blot analysis.}

Northern transfer was performed as described by Sambrook et al. (1989). RNA of OY-W diseased and OY-M diseased garland chrysanthemum was separated by agarose gel electrophoresis and transferred to nylon membrane. Hybridization and detection were also carried out with the DIG luminescent detection kit (Boehringer Mannheim Biochemicals). Probe, hybridization buffer, and washing conditions at detection were the same as described for Southern hybridization. However, temperature at hybridization was raised to $50^{\circ} \mathrm{C}$.

\section{ACKNOWLEDGMENTS}

We thank Shigeru Hatano for his excellent technical assistance. This work was supported by the Program for Promotion of Basic Research Activities for Innovative Biosciences (PROBRAIN), Japan.

\section{LITERATURE CITED}

Altschul, S. F., Gish, W., Miller, W., Myers, E. W., and Lipman, D. J. 1990. Basic local alignment search tool. J. Mol. Biol. 215:403-10.

Archer, G. L., and Johnston, J. L. 1983. Self-transmissible plasmids in staphylococci that encode resistance to aminoglycosides. Antimicrob. Agents Chemother. 24:70-77.

Asaka, O., Ano, T., and Shoda, M. 1994. A rapid and simple method for plasmid copy number comparison. Biotechol. Tech. 8:865-868.

Chomczynski, P. 1993. A reagent for the single-step simultaneous isolation of RNA, DNA and proteins from cell and tissue samples. Biotechniques 15:532-536.

Coffey, A., Harrington, A., Kearney, K., Daly, C., and Fitzgerald, G. 1994. Nucleotide sequence and structural organization of the small, broad-host-range plasmid pCI411 from Leuconostoc lactis 533 . Microbiology 140:2263-2269.

Davies, J. E., and Rownd, R. 1972. Transmissible multiple drug resistance in Enterobacteriaceae. Science 176:758-768.

de Vries, J., and Wackernagel, W. 1993. Cloning and sequencing of the Serratia marcescens gene encoding a single-stranded DNA-binding protein (SSB) and its promoter region. Gene 127:39-45.

del Solar, G., Moscoso., M., and Espinosa, M. 1993. Rolling circlereplicating plasmids from gram-positive and gram-negative bacteria: A wall falls. Mol. Microbiol. 8: 789-796.

Hemmati, K. 1977. The ultrastructural, biological and cytopathological features of the aster yellows agents in situ in the aster plant Callistephus cinensin (L.), and the leafhopper vector, Macrosteles fascifrons (Stal). Ph.D. thesis. University of California, Davis.

Horinouchi, S., and Weisblum, B. 1982. Nucleotide sequence and functional map of pE194, a plasmid that specifies inducible resistance to macrolide, lincosamide, and streptogramin type B antibiotics. J. Bacteriol. 150:804-814.

Ilyina, T. V., and Koonin, E. V. 1992. Conserved sequence motifs in the initiator proteins for rolling circle DNA replication encoded by diverse replicons from eubacteria, eukaryotes and archaebacteria. $\mathrm{Nu}$ cleic Acids Res. 20:3279-3285.

Janniére, L., Gruss, A., and Ehrlich, S. D. 1993. Plasmids. Pages 625644 in: Bacillus subtilis and Other Gram-Positive Bacteria. A. L. Sonenshein, J. A. Hoch, and R. Losick, eds. American Society for Microbiology, Washington, DC.

Jensen, D. D. 1959. A plant virus lethal to its insect vector. Virology 8: 164-175.

King, K. W., and Dybvig, K. 1992. Nucleotide sequence of Mycoplasma mycoides subspecies mycoides plasmid pKMK1. Plasmid 28:86-91.

Kirkpatrick, B. C. 1992. Mycoplasma-like organisms: plant and invertebrate pathogens. Pages 4050- 4067. in: The Prokaryotes. 2nd ed. A. Balows, H. G. Truper, M. Dworkin, W. Harder, and K. H. Schleifer, eds. Springer-Verlag, New York.

Krueger, S. K., and Williams, D. E. 1995. Quantitation of digoxigeninlabeled DNA hybridized to DNA and RNA slot blots. Anal. Biochem. 229:162-169.

Kuske, C. R., and Kirkpatrick, B. C. 1990. Identification and characterization of plasmids from the western aster yellows mycoplasmalike organism. J. Bacteriol. 172:1628-1633.

Lacks, S. A., Lopez, P., Greenberg, B., and Espinosa, M. 1986. Identification and analysis of genes for tetracycline resistance and replication functions in the broad-host-range plasmid pLS1. J. Mol. Biol. 192: 753-765.

Lee, I.-M., and Davis, R. E. 1988. Detection and investigation of genetic relatedness among aster yellows and other mycoplasmalike organisms by using cloned DNA and RNA probes. Mol. Plant-Microbe Interact. 1:303-3110.

Maniloff, J. 1988. Mycoplasma viruses. Crit. Rev. Microbiol. 15:339-389.

McCoy, R. E., Caudwell, A., Chang C. J., Chen, T. A., Chiykowski, L. N., Cousin, M. T., Dale J. L., de Leeuw, G. T. N., Golino, D. A., Hackett, K. J., Kirkpatrick, B. J., Marwitz, R., Petzold, H., Sinha, R. C., Sugiura, M., Whitcomb, R. F., Yang, I. L., Zhu, B. M., and Seemüller, E. 1989. Plant diseases associated with mycoplasma-like organisms. Pages 546-640 in: The Mycoplasmas. Vol. 5. R. F. Whitcomb and J. G. Tully, eds. Academic Press, New York.

Meyer, R. R., and Laine, P. S. 1990. The single-stranded DNA binding protein of Escherichia coli. Microbiol. Rev. 54:342-380.

Morton, T. M., Eaton, D. M., Johnston, J. L., and Archer, G. L. 1993. DNA sequence and units of transcription of the conjugative transfer gene complex (trs) of Staphylococcus aureus plasmid pGO1. J. Bacteriol. 175:4436-4447

Moscoso, M., Eritja, R., and Espinosa, M. 1997. Initiation of replication of plasmid pMV158: Mechanisms of DNA strand-transfer reactions mediated by the initiator RepB protein. J. Mol. Biol. 268: 840-856.

Nakashima, K., and Hayashi, T. 1997. Sequence analysis of extrachromosomal DNA of sugarcane white leaf phytoplasma. Ann. Phytopathol. Soc. Jpn. 63:21-25

Namba, S., Kato, S., Iwanami, S., Oyaizu, H., Shiozawa, H., and Tsuchizaki, T. 1993. Detection and differentiation of plant-pathogenic mycoplasmalike organisms using polymerase chain reaction. Phytopathology 83:786-791.

Ogasawara, N., Nakai, S., and Yoshikawa, H. 1994. Systematic sequencing of the 180 kilobase region of the Bacillus subtilis chromosome containing the replication origin. DNA Res. 1:1-14.

Panopoulos, N., and Peet, R. C. 1985. The molecular genetics of plant pathogenic bacteria and their plasmids. Annu. Rev. Phytopathol. 23: 381-419.

Presecan, E., Moszer, I., Boursier, L., Cruz Ramos, H., de la Fuente, M. F., Hullo, C., Lelong, C., Schleich, S., Sekowska, A., Song, B. H., Villani, G., Kunst, F., Danchin, A., and Glaser, P. 1997. The Bacillus subtilis genome from gerBC (311 degrees) to licR (334 degrees). Microbiology 143:3313-3328.

Razin, S. 1985. Molecular biology and genetics of mycoplasmas (Mollicutes). Microbiol. Rev. 49:419-455.

Sambrook, J., Fritsch, E. F., and Maniatis, T. A. 1989. Molecular Cloning: A Laboratory Manual. 2nd ed. Cold Spring Harbor Laboratory, Cold Spring Harbor, NY.

Shiomi, T., Tanaka, M., Wakiya, H., and Zenbayashi, R. 1996. Occurrence of Welsh onion yellows. Ann. Phytopathol. Soc. Jpn. 62:258-260.

Smith, C. A., and Thomas, C. M. 1984. Nucleotide sequence of the trfA gene of broad host-range plasmid RK2. J. Mol. Biol. 175:251-262.

te Riele, H., Michel, B., and Ehrlich, S. D. 1986. Single-stranded plasmid DNA in Bacillus subtilis and Staphylococcus aureus. Proc. Natl. Acad. Sci. USA 83:2541-2545.

Thompson, J. D., Higgins, D. G., and Gibson, T. J. 1994. Clustal W: Improving the sensitivity of progressive multiple sequence alignment through sequence weighting, positions-specific gap penalties and weight matrix choice. Nucleic Acid Res. 22:4673-4680.

Tsai, J. H. 1979. Vector transmission of mycoplasmal agents of disease. Pages 266-309 in: The Mycoplasmas. Vol. 3. R. F. Whitcomb and J. G. Tully, eds. Academic Press, New York.

Villafane, R., Bechhofer, D. H., Narayana, C. S., and Dubnau, D. 1987. Replication control genes of plasmid pE194. J. Bacteriol. 169:48224829.

Winans, S. C. 1992. Two-way chemical signaling in Agrobacteriumplant interactions. Microbiol. Rev. 56:12-31. 